\title{
Research of Woody Biomass Drying Process in Pellet Production
}

\author{
Jevgenijs Selivanovs ${ }^{1}$, Dagnija Blumberga ${ }^{2}$, Jelena Ziemele ${ }^{3}$, Andra Blumberga ${ }^{4}$, Aiga Barisa ${ }^{5},{ }^{1-5}$ Institute of Energy \\ Systems and Environment, Riga Technical University
}

\begin{abstract}
This paper presents results of experimental research on wood chips and sawdust drying in a rotary dryer. Empirical models for the assessment of two dependent parameters of the drying process were created based on the results of experimental data.

The mathematical description of the relationship between the independent variable - reduced sawdust moisture content - and dependent variable - specific fuel consumption - is represented by a linear equation.
\end{abstract}

Keywords - drying process, wood chips, flue gas, moisture content, rotary dryer, temperature

\section{INTRODUCTION}

Development and use of clean and renewable energy sources is fundamental towards reducing fossil fuel dependence and negative impact on the environment.

Wood pellets are an example of a clean renewable energy source and are considered as one of the fossil fuel substitutes [1]. Mixed biomass pellets have proven to be a more sustainable source of energy in international markets and with the appropriate support, these fuels have much potential in the future. The use of biomass pellets creates new market opportunities in the agricultural sector, reduces dependence on fossil fuels and cuts greenhouse gas emissions associated with their use [2].

Techno-economical analysis is always the starting point of a wood pellet production unit. Additional suggestions related to optimal plant localization and to the best use of the woody pellets as substitute of fossil fuels for heating, cooling and power generation purposes present alternatives with a positive impact of the whole action on the quality of the environment and on the recovery of soil fertility [3].

The moisture content of raw biomass is usually $30-60 \%$. The material needs to be dried to circa $10-15 \%$ moisture content since dry biomass provides considerable benefits for combustion, such as improved operational parameters of the boiler and increased energy efficiency as well as reduced flue gas emissions, compared to fuels with high moisture. However, drying is an energy-intensive process.

From another point of view, drying is a major and challenging step in the pre-treatment of biomass for production of second generation synfuels for transport. Fagernäs et al. [4] define a concept for biomass pre-treatment in two different cases:

- a large-scale wood-based gasification synfuel production with a pneumatic conveying steam dryer;
- a small-scale pyrolysis process based on wood chips and miscanthus bundles with flue gas as a drying medium in a direct or indirect rotary dryer.

Dryers operate on the principle of simultaneous heat and mass transfer where water is removed from the product. A variety of biomass drying equipment is available on the market [5]. The most common biomass dryers applied in bioenergy plants are direct rotary dryers, but the use of steam drying technology is increasing [4].

Construction parameters and performance of the dryer are important factors affecting end-product quality, consumption of energy resources, and environmental and economic costs. Another important aspect to consider is the raw material of wood pellets. E.g., the use of sawmill residues for wood pellet production can be seen both as an environmental solution and as an extra economic benefit. The latter can be determined based on the production costs of wood pellets and energy consumption under different framework conditions [1].

The quality and properties of wood pellets depend on drying technology that is chosen for particular application. The most common biomass dryers use the principle of convection. Advantages and disadvantages of different drying technologies are evaluated based on such parameters as the drying medium, temperature and residence time. Selection of parameters depends on requirements of end-user equipment (boiler, oven or other) [6]. Hanning et al. [7] have calculated a 3-4 years payback time on the initial investment for two types of drying technologies of $40 \mathrm{MW}$ power plants: utilization of flue gases and application of superheated steam.

Several authors discuss the effect of drying technology on pellet quality. For example, Ståhl et al. [6] evaluated the impact of two parameters - the moisture content and the emissions of volatile hydrocarbons - on the quality properties of wood pellets. Authors concluded that the level of volatile hydrocarbon emissions after drying depends on the residence time of sawdust in the dryer: drying technologies with longer residence time resulted in larger emissions of terpenes. Furthermore drying techniques can also affect the environment. Low emissions of volatile hydrocarbons would improve the energy content of the sawdust, and by decreasing air pollution improve the work environment and the environment in the surroundings of the dryers [6].

\section{Modeling OF Drying Process}

Tasks of modelling of drying processes are several: to find optimal parameters of drying process, to keep high quality of 
product and to reach minimum consumption of energy resources.

Specific fuel consumption in this case is selected as energy efficiency indicator (Eq. 1) which depends on fuel consumption and the product produced.

$$
b=\frac{B}{M_{2 \text { prod }}}
$$

where

$\mathrm{b}$ - specific fuel consumption, $\mathrm{kg} / \mathrm{t}_{\text {prod; }}$;

$\mathrm{M}_{2 \text { prod }}$ - amount of dried material for the production of pellets, $\mathrm{kg} / \mathrm{h}$;

$\mathrm{B}$ - fuel consumption, $\mathrm{kg} / \mathrm{h}$.

Fuel consumption or the necessary amount of dried material for the operation of the furnace required for the drying process is calculated as follows:

$$
B=\frac{Q_{d}}{L H V \cdot \eta_{f}}
$$

where

LHV - lower heating value of fuel, $\mathrm{MWh} / \mathrm{t}$;

$\mathrm{Q}_{\mathrm{d}}$ - heat capacity required for drying, $\mathrm{MW}$;

$\eta_{\mathrm{f}}-$ furnace efficiency coefficient.

The given values for the calculation of the drying process are usually the amount of material, its moisture content at the inlet and outlet, temperatures and inlet parameters of the drying agent. Other group of parameters is following: the values of dried moisture content, weight change of the material during the drying process, drying agent consumption and heat consumption. These values can be obtained from the material and heat balance of drying process. The average drying agent parameter values are used for the calculation of the dryer.

First the amount of dried material is calculated using (3).

$$
M_{2}=M_{2 \text { prod }}+B
$$

where

$\mathrm{M}_{2}$ - total quantity of dried material after the dryer, $\mathrm{kg} / \mathrm{h}$.

Further dried moisture is determined using following equation:

$$
W=M_{2} \frac{W_{1}-W_{2}}{100-W_{1}}=M_{1} \frac{W_{1}-W_{2}}{100-W_{2}}
$$

where

$\mathrm{W}$ - dried moisture, $\mathrm{kg}$ water;

$\mathrm{W}_{1}$ - average moisture content of wood chips before the dryer, $\%$;

$\mathrm{W}_{2}$ - average moisture content of wood chips after the dryer, $\%$;

$\mathrm{M}_{1}$ - total amount of wet wood chips before the dryer, $\mathrm{kg} / \mathrm{h}$.
Knowing the amount of dried moisture, the amount of dry material after the dryer and moisture content of wood chips, the amount of wet wood chips before the dryer can be calculated using (5).

$$
M_{1}=\frac{W}{W_{1}-W_{2}}\left(100-W_{2}\right)
$$

Consumption of drying agent is calculated following:

$$
L=\frac{1000 W}{d_{2}-d_{1}}
$$

where

$\mathrm{L}$ - consumption of drying agent, $\mathrm{kg} / \mathrm{h}$;

$\mathrm{d}_{1}-$ moisture content of drying agent before the dryer, $\mathrm{g} / \mathrm{kg}$ dry gas;

$d_{2}-$ moisture content of drying agent after the dryer, $g / k g$ dry gas

The consumption of the drying agent is usually attributed to $1 \mathrm{~kg}$ of moisture excreted in drying process, according to (7).

$$
l=\frac{L}{W}=\frac{1000}{d_{2}-d_{1}}
$$

where

1 - specific consumption of drying agent, $\mathrm{kg}$ dry gas $/ \mathrm{kg}$ water.

Heat consumption is determined using the heat balance of the dryer. Heat consumption is attributed to $1 \mathrm{~kg}$ of water. Dryer heat consumption $\mathrm{q}$ consists of heat $\mathrm{q}_{\mathrm{k}}$, which is supplied from the furnace, because there are no additional heaters in the dryer (Eq.8).

$$
q=q_{f}
$$

where

$\mathrm{q}$ - dryer heat consumption, $\mathrm{kJ} / \mathrm{kg}$ water;

$\mathrm{q}_{\mathrm{f}}-$ heat supplied from the furnace, $\mathrm{kJ} / \mathrm{kg}$ water.

Heat supplied from the furnace is calculated as follows [1]:

$$
q_{f}=l\left(H_{1}-H_{0}\right)
$$

where

$\mathrm{H}_{1}$ - enthalpy of drying agent before the dryer, $\mathrm{kJ} / \mathrm{kg}$ dry gas;

$\mathrm{H}_{0}$ - enthalpy of drying agent before the furnace inflow, $\mathrm{kJ} / \mathrm{kg}$ dry gas.

Dryer heat consumption and heat that will be supplied from the furnace can be calculated using the equation:

$$
q=q_{f}=l\left(H_{2}-H_{0}\right)+q_{l}
$$

where 
$\mathrm{H}_{2}$ - enthalpy of drying agent in the outflow of the dryer, $\mathrm{kJ} / \mathrm{kg}$ drygas;

$\mathrm{q}_{1}$ - heat loss from the dryer surface, $\mathrm{kJ} / \mathrm{kg}$ water.

Heat consumption for heating the material and the amount of heat input with material moisture are not significant and compensate each other.

Heat loss from the dryer surface is calculated using (11).

$$
q_{l}=\frac{Q_{S}}{W}
$$

where

$\mathrm{Q}_{\mathrm{S}}$ - heat loss capacity from dryer surface, $\mathrm{W}$ or $\mathrm{kJ} / \mathrm{h}$.

Dryer efficiency (the useful heat) is calculated following:

$$
\eta_{d}=1-\frac{q_{l}}{q}
$$

where

$\eta_{d}-$ dryer efficiency coefficient.

Enthalpy of drying agent after the dryer cannot be determined with the help of H-d diagram, therefore (13) is used to calculate it.

$$
H_{2}=l\left(q_{f}-q_{l}\right)+H_{0}
$$

Enthalpy of drying agent after the dryer for each separate measurement is determined using the following equation:

$$
H_{2 n}=H_{1 n} \eta_{d}
$$

where

$\mathrm{H}_{2 n}$ - enthalpy of drying agent after the dryer for individual measurement, $\mathrm{kJ} / \mathrm{kg}$ dry gas;

$\mathrm{H}_{1 n}$ - enthalpy of drying agent before the dryer for an individual measurement, $\mathrm{kJ} / \mathrm{kg}$ dry gas.

Knowing the drying agent parameters, internal heat balance of the dryer can be calculated:

$$
\Delta=l\left(H_{2}-H_{1}\right)
$$

where

$\Delta$ - internal heat balance of the dryer.

Internal heat balance of the dryer determines the relationship between additional heat input and heat loss. There are three possible scenarios for a real dryer:

- If $\Delta=0$, additional heat input in the dryer covers all heat loss. Drying takes place at a constant drying agent enthalpy, that is, $\mathrm{H}_{1}=\mathrm{H}_{2}=$ const

- If $\Delta>0$, additional heat not only covers all heat loss from dryer, but also increases the enthalpy of drying agent. That is $\mathrm{H}_{2}>\mathrm{H}_{1}$
- If $\Delta<0$, additional heat does not cover all heat loss from dryer (or there is no additional heat input) and the enthalpy of drying process decreases, $\mathrm{H}_{2}<\mathrm{H}_{1}$.

By multiplying the moisture exerted in the dryer with the heat consumption of the dryer we obtain heat capacity necessary for the drying process.

$$
Q_{d}=W \cdot q
$$

where

$\mathrm{Q}_{\mathrm{d}}-$ heat capacity necessary for the drying process, MW.

\section{Data Processing And Result Assessment Model}

An experiment was carried out in industrial conditions with a rotary dryer of sawdust and a wood chips furnace for generation of flue gases used as drying agent.

The model of data processing and result assessment includes experimentally measured data and an evaluation module that allows identifying potential solutions for operational improvements in the dryer. The algorithm of the model is presented in Figure 1.

Experimental data included measurements of the following parameters: outdoor temperature, inlet and outlet temperatures of gases, moisture content of raw material (wood chips and sawdust) and the product (wood pellets) at the inlet and outlet, capacity of dryer, and fuel consumption.

Calculations were carried out by applying equations describing the drying process presented in the chapter above. Statistical processing of data was performed to find analytical and graphical correlations between the variables. The relationship between independent and dependent variables was characterized by a regression model.

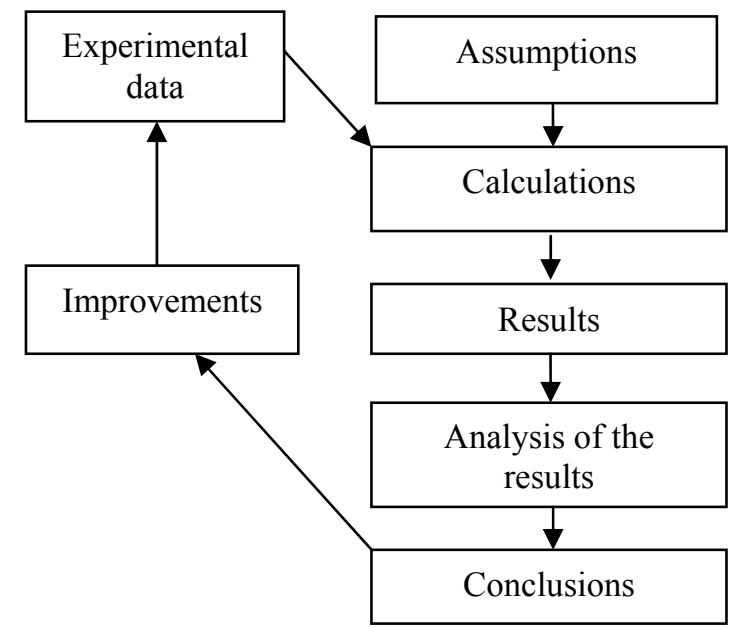

Fig. 1. The model of data processing and result evaluation

Two types of models were used for data processing: a single factor linear model and a multifactor linear model. Mathematical methods of statistics (correlation and regression analysis) were extensively used to acquire these correlations. Statistical data processing was performed in a specific order characterized below $[8,9]$ : 
- Determination of the regression equation for the phenomena at issue. For this purpose, the most commonly used is the method of least squares;

- Statistical analysis of the resulting regression coefficient to assess its significance in the equation. This part of analysis is carried out with help of regression analysis, and;

- Identification of the independent and dependent variables of casual interaction (stochastic connections) closeness (correlation).

On the basis of empirical models, an evaluation of obtained data was done and relation between parameters was found. Results of the experiment presented necessity to improve process parameters of the drying technology. Therefore a repeated industrial experiment was carried out.

\section{RESULTS}

In this case regression equations corresponding to empirical correlation extraction and verification methodology were used. Based on the results, conclusions about the performance of equipment and necessary improvements to optimize designed performance were drawn. A few ideas are presented further.

The quality of pellets is affected by various parameters of the drying process. Results of the research present a linear dependence of pellet moisture content from flue gas saturation with water vapour (see Figure 2).

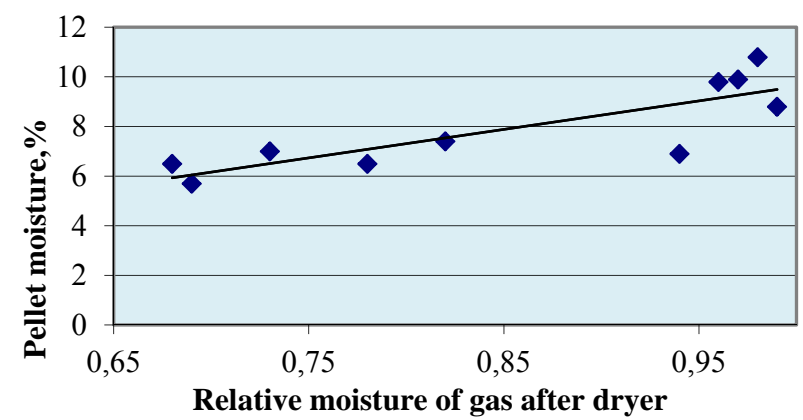

Fig. 2. Effect of flue gas saturation with water vapour on moisture content of pellets

Figure 2 shows good correlation between data presenting moisture content of pellets and relative moisture of gas after the dryer $\left(\mathrm{R}^{2}=0.7\right)$. Relation between both parameters indicates that lower level of flue gas moisture results in lower moisture content of pellets. Interconnection between the independent variable (gas saturation) and dependent variable (moisture content of pellets) is mathematically described by equation:

$$
W_{p e l}=11.47 \varphi_{2}-1.873
$$

\section{where}

$\mathrm{W}_{\text {pel }}$ - pellet moisture content, $\%$;

$\varphi_{2}$ - relative moisture of gas after dryer.

Energy efficiency of the drying process depends from the moisture content of raw material and parameters of the drying process: inlet and outlet temperatures, quality and efficiency of combustion process and other factors.

Energy efficiency analysis of the drying process indicates changes in specific energy consumption. This energy efficiency indicator allows using a dependent variable - heat required to evaporate one percent of moisture from sawdust. The difference between initial and final moisture content of sawdust is selected as the independent variable in this case.

Data in Figure 3 show acceptable correlation between specific heat energy consumption per each percent of reduced sawdust moisture and the range of reduced sawdust moisture content in percents $\left(\mathrm{R}^{2}=0.44\right)$. The results indicate that moisture content of pellets can be reduced at a higher level with minimal specific heat consumption. The mathematical description of interconnection between the independent variable - reduced sawdust moisture content - and dependent variable - specific heat consumption per unit of reduced moisture in raw material - is presented by the equation:

$$
q_{h c}=2.503-0.038 d W_{\text {sdust }}
$$

where

$\mathrm{dW}_{\text {sdust }}-$ reduced sawdust moisture content, $\%$; $\mathrm{q}_{\mathrm{hc}}$ - heat energy consumption per each percent of reduced pellet moisture content, $\mathrm{kJ} / \%$.

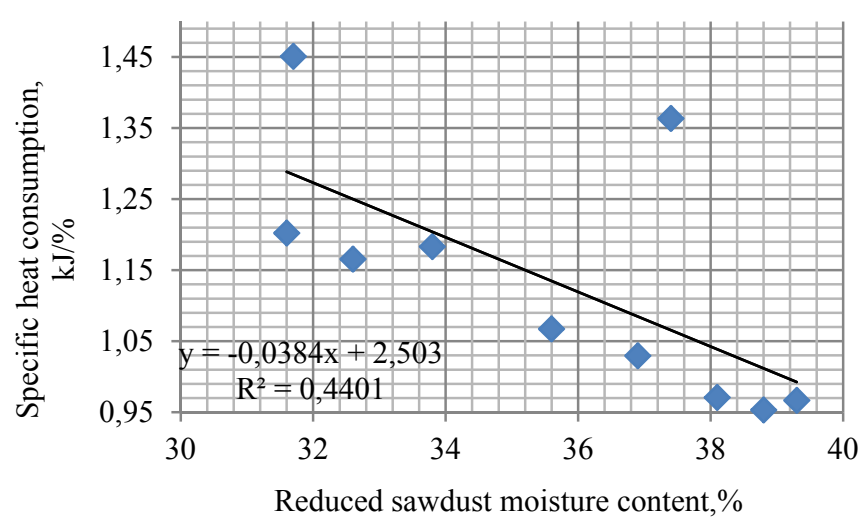

Fig. 3. Specific heat energy consumption depending on reduced sawdust moisture content

\section{DISCUSSIONS}

Results of the experimental research allow proposing a number of substantial improvements in the drying processes and technologies related to improved energy efficiency by using waste products for pellet production and dryer material in combustion process. It allows obtaining less moist endproduct due to reduced relative moisture content of flue gases.

Energy efficiency analysis of the drying process, presented in Figure 3, allows proposing for operational changes in process parameters to reach higher reduction of moisture in raw material at inlet and outlet of the dryer with minimal specific heat consumption.

The third proposal for improvements is related to reduction of moisture content in flue gases. This can be realized by condensing the vapour contained in flue gases after the dryer before the stack. The resulting heat energy can be used in the 
drying process. An additional advantage is the increased quality of pellets due to partial return of dry flue gases to the dryer.

\section{CONCLUSIONS}

1. Research on the woody biomass drying process has allowed finding dependence of qualitative parameters and energy efficiency indicators of the drying process from independent variables - parameters of processes.

2. Relation between two important drying process parameters shows that lower moisture content of pellets can be reached at minimal level of flue gas moisture. A mathematical description of interconnection between the independent variable - gas saturation - and dependent variable - pellet moisture content - presents a linear equation.

3. Dependence of energy efficiency on reduced moisture content of sawdust proves that higher level of moisture reduction in raw material can be reached at minimal specific heat consumption. The mathematical description of interconnection between the independent variable - reduced sawdust moisture content - and dependent variable - specific fuel consumption presents a linear equation.

\section{REFERENCES}

1. Uasuf A., Becker G. Wood pellets production costs and energy consumption under different framework conditions in Northeast Argentina / Biomass and Bioenergy Vol. 35, Issue 3, March 2011, Pages 1357-1366

2. Karkania V., Fanara E., Zabaniotou A. Review of sustainable biomass pellets production - A study for agricultural residues pellets' market in Greece Review Article / Renewable and Sustainable Energy Reviews, Volume 16, Issue 3, April 2012, Pages 1426-1436

3. Di Giacomo G., Taglieri L. Renewable energy benefits with conversion of woody residues to pellets Original Research Article / Energy, Vol. 34, Issue 5, May 2009, Pages 724-731

4. Fagernäs L., Brammer J., Wilén C. et.al Drying of biomass for second generation synfuel production /Biomass and Bioenergy Vol.34, Issue 9, September 2010, Pages 1267-1277

5. Couper J.R., Penney W.R., Fair J.R.et. al. Dryers and Cooling Towers/Chemical Process Equipment (Third Edition) 2012, Pages 223-275

6. Ståhl M., Granström K., Berghel J. et.al. Industrial processes for biomass drying and their effects on the quality properties of wood pellets/ Biomass and Bioenergy Vol. 27, Issue 6, December 2004, Pages 621-628

7. Li H., Chen Q., Zhang X. et.al. Evaluation of a biomass drying process using waste heat from process industries: A case study / Applied Thermal Engineering Vol.35, March 2012, Pages 71-80

8. Revina I. Ekonometrija - Rịga: Latvijas Universitāte, 2002. - 270 lpp.

9. Veidenbergs I., Blumberga A. Ēku energopatēriņa regresijas modelis // Proceedings of International Scientific Conference 'Power and Electrical Engineering',October 11-13, 2001 - Riga: RTU, 2001. Pages. 125-130

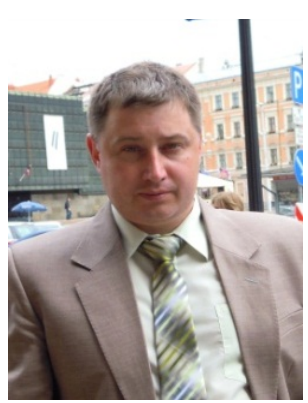

Jevgenijs Selivanovs, M.sc.ing., Riga Technical University, Institute of Energy Systems and Environment. Jevgenijs has Master's degree in Environmental Science. He is working in company 'Ludzas Bio-Energija' as a Manager of biomass boiler house and in pellet production company 'Ekobriketes' as a Managing Director. The main research area of Jevgenijs is energy saving solutions.

Address: Kronvalda Blvd. 1, LV-1010, Riga, Latvia

E-mail: 1be@latnet.lv

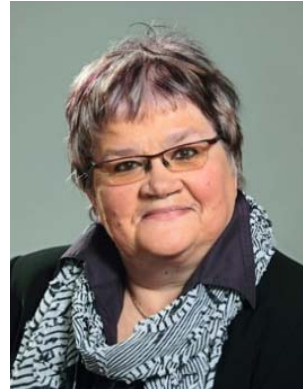

Dagnija Blumberga, Dr.hab.sc.ing., Professor, Riga Technical University, Institute of Energy Systems and Environment. Prof. Dagnija Blumberga acquired diploma in Thermal Engineering in 1970. Her two steps doctoral degree 'Condensing Unit' was defended in Lithuanian Energy Institute (1988) and Doctor Habilitatus thesis 'Analysis of Energy Efficiency from Environmental, Economical and Management Aspects' was prepared in Royal Institute of Technology in Stockholm (1995) and defended in Riga Technical University (1996). The main research area is renewable energy resources. She has participated in many local and international projects related to energy and environment. She is author of more than 200 publications and 14 books.

E-mail: dagnija.blumberga@rtu.ly

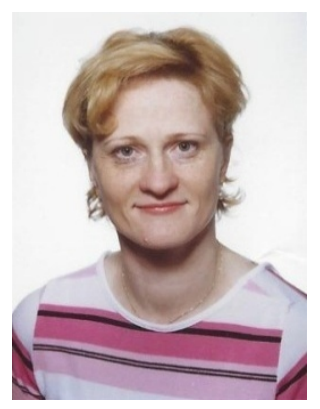

Jelena Ziemele, M.sc.ing., Riga Technical University, Riga International School of Economics and Business Administration. Jel̦ena has Master's degree in Thermal Technique and Master's degree in Business Administration. She started Master studies in Environmental Science in Institute of Energy Systems and Environment in 2011.

She has worked in Academy of Science Institute of Microbiology as Scientific Assistant, JSC 'Ligija Teks' as Manager of boiler and turbine house, and in JSC 'Latvijas Gāze' as the Main Engineer.

The main research area is energy efficient technologies and environmentally friendly solutions.

Phone: +371 29120969

E-mail: ziemele-1@inbox.lv

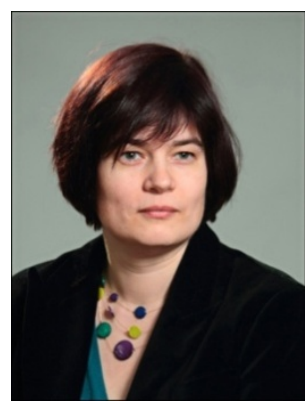

Andra Blumberga, Dr.sc.ing., professor, has been part of academic staff of Institute of Energy Systems and Environment, Faculty of Power and Electrical Engineering, Riga Technical University since 2001. Her main research area is end-users energy efficiency. She started her professional career as Energy Auditor in Sloka pulp and paper factory in 1991-1993. It was followed by a six-year employment in ABB Latvia as Manager of Ventilation and Refrigeration Dept. From 1999-2008 Prof. Blumberga has been Director of energy and environmental consulting company Ekodoma Ltd., where she is still acting as a consultant. She has participated in different local and international projects related to energy and environment, and is author of many publications and books. She acquired Engineer and M.Sc. Diploma in Faculty of Civil Engineering, Riga Technical University and $\mathrm{PhD}$ degree in Faculty of Power and Electrical Engineering, Riga Technical University (2001).

E-mail: andra.blumberga@rtu.lv

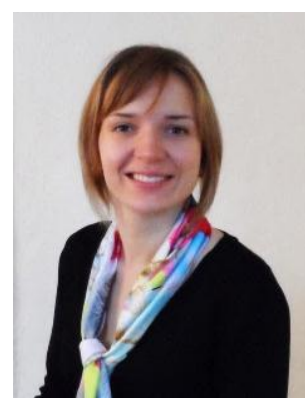

Aiga Barisa, M.sc., Riga Technical University, Institute of Energy Systems and Environment. Aiga acquired Bachelor's degree in Environmental Science in 2010 and Master's degree in 2012. Both bachelor and master theses were dedicated to promotion of renewable energy sources in Latvian district heating systems. She has working experience as a Scientific Assistant in Riga Technical University and as a Project Assistant in engineer consulting company. Currently she is a $\mathrm{PhD}$ student at Institute of Energy Systems and Environment. The main research area is renewable energy sources. Aiga Barisa is co-author of nine scientific papers.

Phone: +37120059433

E-mail: aiga.barisa@rtu.lv 